\title{
Solitary Papillary Muscle Hypertrophy: A New Echo-Electrocardiographic Syndrome?
}

\section{A Case Report}

J. Ker, MRCP (Edinburgh), PhD, Pretoria, South Africa

Hypertrophic cardiomyopathy is the term for a heterogeneous group of disorders for which various mutations of genes involving proteins of the cardiac sarcomere lead to hypertrophy of various segments of the left ventricle. The hypertrophy can involve the left and/or right ventricle, be symmetric or asymmetric, involving the septum, free wall, mid-ventricle, or apex. The phenomenon of solitary papillary muscle hypertrophy is rare with only 2 references in the literature. Furthermore, giant negative $\mathrm{T}$ and $\mathrm{U}$ waves are 2 common electrocardiographic phenomena in hypertrophic cardiomyopathy and have been attributed to hypertrophy of the posterior papillary muscle. Solitary hypertrophy of the anterior papillary muscle might be a new echo-electrocardiographic syndrome.

\section{Introduction}

Hypertrophic cardiomyopathy $(\mathrm{HCM})$ is genotypically and phenotypically a highly heterogeneous disorder. ${ }^{1-3}$ In this condition, various mutations in genes coding for proteins of the cardiac sarcomere manifest as left ventricular hypertrophy without obvious cause. ${ }^{1-} 3$ In the Familial Hypertrophic Cardiomyopathy Database, more than 150 mutations, scattered throughout 10 genes encoding proteins of the cardiac sarcomere, are listed as causes of HCM. ${ }^{3}$ The phenotypic manifestation of HCM is equally diverse: the hypertrophy may affect the left and/or right ventricle and can be symmetrical or asymmetrical. ${ }^{1}$ Septal hypertrophy is the most common type of asymmetrical hypertrophy, with midventricular and apical hypertrophy being less common. 1

Kobashi et $\mathrm{al}^{4}$ noted that patients can present with isolated papillary muscle hypertrophy and suggested that this is either a newly identified subtype of HCM or, alternatively, that this is simply an early form of HCM. In that same year (1998), Reddy et al ${ }^{5}$ described a case of apical hypertrophic cardiomyopathy. However, Suwa and Kobashi6 noted that the case actually had typical features of solitary papillary muscle hypertrophy. Since then, no case reports of solitary 
papillary muscle hypertrophy were found in the literature, and the question of whether this entity truly represents a subtype of HCM remains.

A 20-year-old Caucasian man was referred to our cardiology department because of an abnormal electrocardiogram (ECG) result (see Figure 1). The ECG revealed a peculiar pattern in lead V4: notching of the QRS complex with elevation of the ST segment and a prominent, positive $U$ wave. The clinical examination, chest $x$-ray, blood urea nitrogen, full blood count, troponin-T, Pro- brain natriuretic peptide, and electrolyte levels were all normal.

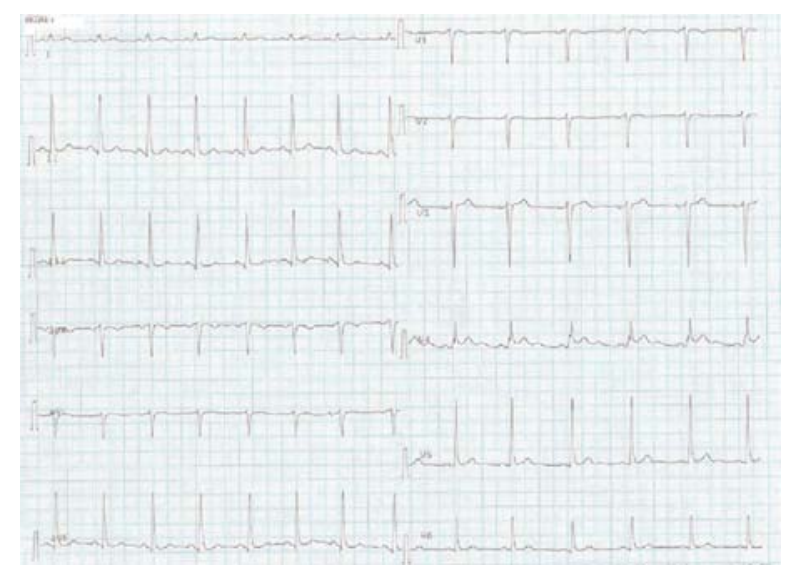

Figure 1. Twelve-lead electrocardiogram. Note the peculiar appearance of lead V4. There is notching of the QRS complex, ST elevation, and a prominent, positive $U$ wave.

Transthoracic, two-dimensional echocardiography revealed isolated hypertrophy of the anterolateral papillary muscle, with an otherwise normal left ventricle with no hypertrophy in any other segment (see Figure 2).

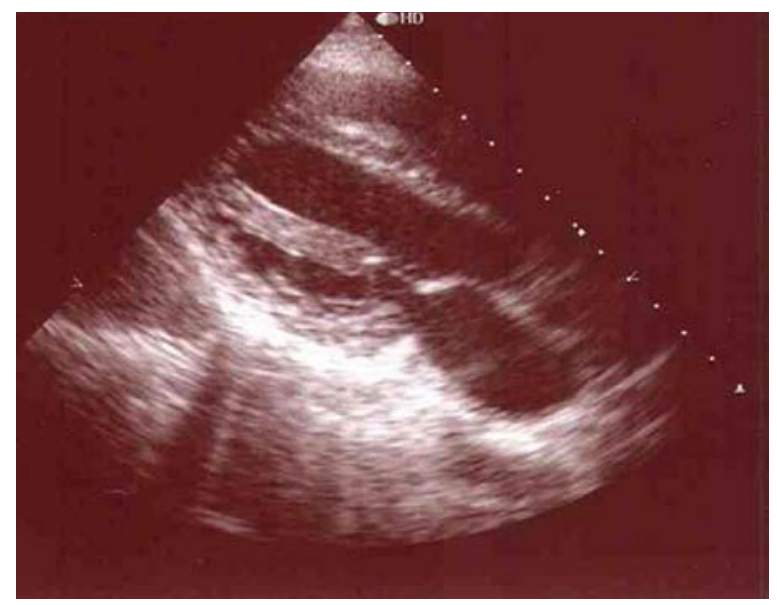

Figure 2. Echocardiogram: parasternal, long-axis view. Note the marked, isolated hypertrophy of the anterior papillary muscle. 
Giant negative $T$ and $U$ waves are two common electrocardiographic findings in $\mathrm{HCM}^{7}$ Hasegawa et $\mathrm{al}^{7}$ reported 2 cases of $\mathrm{HCM}$ as a possible explanation for these electrocardiographic changes in $\mathrm{HCM}$. In the first patient, giant negative $\mathrm{T}$ and $\mathrm{U}$ waves became evident only after the appearance of posterior papillary muscle hypertrophy, and in the second patient, these waves disappeared following posterior wall infarction, which involved the posterior papillary muscle.

In this case, a prominent, positive $\mathrm{U}$ wave was accompanied by ST elevation and notching of the QRS complex in lead V4, with marked hypertrophy of the anterior papillary muscle. Might this be the first of a new echo-electrocardiographic syndrome?

\section{REFERENCES}

1.Wigle ED, Rakowski H, Kimball BP, Williams W: Hypertrophic cardiomyopathy: clinical spectrum and treatment. Circulation 92:1680-1692, 1995.

2.Runge MS, Stouffer GA, Sheahan RG, Lerakis S: Hypertrophic cardiomyopathy: presentation and pathophysiology. Circulation 314:324-329, 1997.

3.Van Driest SL, Ackerman MJ, Ommen SR, et al: Prevalence and severity of benign mutations in the beta-myosin heavy chain, cardiac troponin $T$ and alpha-tropomyosin genes in hypertrophic cardiomy-opathy. Circulation 106:3085-3090, 2002.

4.Kobashi A, Suwa M, Ito $\mathrm{T}$, Otake $\mathrm{Y}$, Hirota $\mathrm{Y}$, Kawamura $\mathrm{K}$ : Solitary papillary muscle hypertrophy as a possible form of hypertrophic cardiomyopathy. Jpn Circ J 62:811-816, 1998.

5.Reddy V, Korcarz C, Weinert L, Al-Sadir J, Spencer KT, Lang RM: Apical hypertrophic cardiomyopathy. Circulation 98:2354, 1998.

6.Suwa M, Kobashi A: Differentiation of solitary papillary muscle hypertrophy from apical hypertrophic cardiomyopathy. Circulation 101:e159, 2000.

7. Hasegawa K, Sawayama T, Nezuo S, Tadaoka S, Kawahara Y, Inoue S: Possible pathogenesis of giant negative $T$ and negative $U$ waves in hypertrophic car-diomyopathy: a report of two cases. J Cardiol 22:271-279, 1992. 